\title{
EDITORIAL PREFACE TO THE SPECIAL ISSUE DEDICATED TO THE MANUFACTURING_2021 CONFERENCE
}

\author{
ISTVÁN GYURIKA ${ }^{1}$ \\ ${ }^{1}$ Research Centre for Engineering Sciences, University of Pannonia, Egyetem u. 10, Veszprém, 8200, \\ HUNGARY
}

The Association of Mechanical Engineers in Hungary, "GTE", has a long tradition in organizing a nation-wide, scientific-technical conference devoted to MANUFACTURING. During the 29-30th October 2021, the University of Pannonia offered to host the 24th GTE MANUFACTURING Conference, where almost 50 presentations were delivered by engineering students with $\mathrm{PhD}$ or Post-Doc level. Participants from industry had also a good opportunity to present their new products and services, thus a fruitful collaboration platform had taken place at the premises of the University of Pannonia.

The highly appreciated Hungarian Journal of Industry and Chemistry is an excellent medium to convey the novelties and new scientific-technical achievements demonstrated during the conference. The $\mathrm{PhD}$ students are also grateful to HJIC for the chances to generate high-level publications at international level.

The presentations were mainly offered in English language, giving additional opportunities for $\mathrm{PhD}$ students to practice oral presentations of their scientific work and achieved results. All of the topics address one or more of the offered areas of manufacturing, including prod-

Correspondence: gyurika@almos.uni-pannon.hu ucts, production, logistics, sensor-, monitoring-, roboticsthematic areas, as well as economic and human aspects, e.g., operator cooperation with robots. The review committee generated detailed feedback to the authors to show higher level of articulation of their ideas and results, and to maintain the scientific high level of the HJIC journal. The selected papers are included in this special issue of HJIC.

The GTE Association will continue to offer its members opportunities to share up-to-date technical and scientific information and build a reliable social-technical network in the new ecosystem needed for the transition from Indutry 4.0 to Industry 5.0. We are looking ahead and inviting for the quad-centenarian, 25th jubilee MANUFACTURING Conference.

István Gyurika

Chairman of GTE's Division of Manufacturing Systems

On behalf of the MANUFACTURING: 2021 Organising Committee. 